Bond University

Research Repository

\title{
Views about sensory modulation from people with schizophrenia and treating staff: A multisite qualitative study
}

Machingura, Tawanda; Lloyd, Chris; Murphy, Karen; Goulder, Sarah ; Shum, David; Green, Heather

Published in:

British Journal of Occupational Therapy

DOI:

$10.1177 / 0308022620988470$

Licence:

Other

Link to output in Bond University research repository.

Recommended citation(APA):

Machingura, T., Lloyd, C., Murphy, K., Goulder, S., Shum, D., \& Green, H. (2021). Views about sensory

modulation from people with schizophrenia and treating staff: A multisite qualitative study. British Journal of Occupational Therapy, 84(9), 550-560. https://doi.org/10.1177/0308022620988470

\section{General rights}

Copyright and moral rights for the publications made accessible in the public portal are retained by the authors and/or other copyright owners and it is a condition of accessing publications that users recognise and abide by the legal requirements associated with these rights.

For more information, or if you believe that this document breaches copyright, please contact the Bond University research repository coordinator. 


\section{TITLE PAGE}

Full title: Views about sensory modulation from people with schizophrenia and treating staff: A multisite qualitative study.

\section{Short title: User views on sensory modulation}

\section{Authors and Affiliations}

1. Tawanda Machingura, $\mathrm{PhD}$ (candidate), BSc(hons), MHPrac(hons)

- Assistant Professor of Occupational Therapy, Bond University, Gold Coast, Queensland, Australia and

- PhD Candidate, Griffith University, School of Applied Psychology, Gold Coast, Australia

2. Chris Lloyd, $\mathrm{PhD}$

- Adjunct Research Fellow Behavioural Basis of Health, Griffith University, Gold Coast campus, Queensland, Australia

3. Karen Murphy, $\mathrm{PhD}$

- Program Director Bachelor of Psychology (Honours) and Bachelor of Psychological Science (Honours) / Senior Lecturer, Griffith University, School of Applied Psychology, Gold Coast, Australia

4. Sarah Goulder, MOT

- Master of Occupational Therapy Student, Bond University, Gold Coast, Australia

5. David Shum, $\mathrm{PhD}$

- Professor, Department of Rehabilitation Sciences, The Hong Kong Polytechnic University, Hong Kong

- Adjunct Professor, Griffith University, Gold Coast campus, Queensland, Australia

6. Heather Green, PhD

- Director (Clinical Psychology Programs)/ Senior Lecturer, Griffith University, School of Applied Psychology, Gold Coast, Australia

Address for correspondence:

Tawanda Machingura

Bond University

2 Promethean Way

Robina, QLD 4226,

Australia

Email: tmaching@bond.edu.au 


\section{Ethics:}

The study commenced after receiving ethical clearance from Gold Coast University

Hospital Human Ethics Review Committee (HREC/17/QGC/151) and Griffith University

Human Research Ethics Committee (GU: 2019/079).

Funding.

This project received funding for transcript translation from Griffith University

(\$2,181.96 AUD) and in-kind support for the materials used by patients for sensory interventions from West Moreton and Gold Coast Hospital and Health Services (est \$1000 AUD).

\section{Acknowledgements}

This research is part of a $\mathrm{PhD}$ project being completed at Griffith University by the first author. The authors would like to acknowledge the input received from Professor Sharon Mickan regarding study design, recruitment, and data collection. The authors would also like to acknowledge the support received from staff at Gold Coast Hospital and Health Service and West Moreton Hospital and Health Service, particularly the following occupational therapists: Chris Thompkins, Eliza Gawne, and Lorraine Dowell.

\section{Conflict of interest statement:}

We know of no conflicts of interest with this publication and there has not been any significant financial support for this work that could influence this publication.

\section{Author contributions}

TM: Scoping the paper, the collection of some of the data, data analysis, synthesizing the literature, writing the first draft, attending to revisions based on reviewer comments.

CL: Scoping the paper, data analysis, reviewing the paper, attending to some of the revisions

KM: Second reviewer for the data, data analysis, reviewing the paper, attending to some of the revisions 
SG: Data collection, reviewing coding, second coder, reviewing the paper

DS: Scoping the paper, data analysis, reviewing the paper, attending to some of the revisions

HG: Scoping the paper, second reviewer for the data, data analysis, reviewing the paper, attending to some of the revisions. 
Title: Views about sensory modulation from people with schizophrenia and treating staff: A multisite qualitative study.

\begin{abstract}
Introduction: Current non-pharmacological treatment options for people with schizophrenia are limited. There is, however, emerging evidence that sensory modulation can be beneficial for this population. This study aimed to gain insight into sensory modulation from the user's and the treating staff's perspective.
\end{abstract}

Method: A qualitative content analysis design was used. Transcripts from occupational therapists $(n=11)$ and patients with schizophrenia $(n=13)$ derived from in-depth semistructured interviews were analysed for themes using content analysis.

Results: Five themes emerged from this study: Service user education on the sensory approach is the key; A variety of tools should be tried; Sensory modulation provides a valued treatment option; There are challenges of managing perceived risk at an organisational level; and There is a shortage of accessible and effective training.

Conclusion: People with schizophrenia and treating staff had congruent perceptions regarding the use of sensory modulation as a treatment option. The findings suggest that sensory modulation can be a valued addition to treatment options for people with schizophrenia. We suggest further research on sensory modulation intervention effectiveness using quantitative methods so these results can be further explored.

Keywords: Schizophrenia, qualitative research, mental health, patient participation, occupational therapists, sensory modulation, psychosocial interventions. 


\section{Introduction}

Despite schizophrenia being a debilitating mental health condition impacting an individual's quality of life and participation in daily activities, current treatment options, including antipsychotic medications, psychosocial therapies, social supports, and rehabilitation are shown to be limited in effectively managing the various symptoms seen within this condition (Lipskaya-Velikovsky, Bar-Shalita, \& Bar, 2015; Owen, Sawa, \& Mortensen 2016). The use of sensory modulation or sensory input in a therapeutic manner to enhance wellbeing, social and occupational functioning has emerged in the last 20 years as a promising intervention for those with severe mental illness including schizophrenia (Champagne, Koomar, \& Olson, 2010; Lipskaya-Velikovsky, Bar-Shalita and Bart, 2015; Scanlan and Novak, 2015). Although spearheaded by occupational therapists, the efficacy of this intervention has however not yet been established to the same standard of evidence as other occupational therapy interventions (Scanlan and Novak, 2015). This study sought to explore sensory modulation experiences from both a service user and a staff perspective. This approach allowed the authors to compare staff views with those of service users and gain a fuller understanding of the efficacy of the intervention than would have been possible with either group alone.

\section{Literature Review}

People with schizophrenia have been found to have sensory impairments affecting multisensory integration (Postmes et al., 2014). Sensory disturbances in schizophrenia often manifest as an inability to process and respond to sensory information in an adaptive and meaningful way (Vlcek et al, 2014). Occupational therapy researchers have also reported on atypical sensory processing patterns in people with schizophrenia (Bar-Shalita et al., 2012; 
Lipskaya-Velikovsky et al., 2014). Research evidence suggests that in people with schizophrenia, super sensitivity and over inhibition exist simultaneously (Brown, Cromwell, Filion, Dunn, \& Tollefson, 2002). Sensory modulation is seen as a promising intervention that can enable those individuals with atypical sensory processing to live a healthier and better quality of life (Bar-Shalita and Bart, 2015; Sinclair, Meredith, Strong, \& Chalkiadis, 2019). This has led to a huge uptake of the intervention in practice, however, the research evidence on the efficacy of sensory modulation interventions has lagged behind other treatment techniques (Bailliard \& Whigham, 2017; Machingura, Shum, Molineux, \& Lloyd, 2018; Scanlan and Novak, 2015).

Sensory modulation (SM) has many definitions in the occupational therapy literature. However, it is generally referred to as the brain's capacity to regulate and organise one's responses to sensory input in a graded and adaptive manner (Champagne et al., 2010; Lipskaya-Velikovsky, Bar-Shalita and Bart, 2015), for the purpose of facilitating effective participation in occupations (Lipskaya-Velikovsky et al., 2015). This twofold process has been confirmed in a recent study that utilised concept analysis and concluded that "It originates in the central nervous system as the neurological ability to regulate and process sensory stimuli; this subsequently offers the individual an opportunity to respond behaviourally to the stimulus" (Brown, Tse, \& Fortune, 2019 p. 521). Brown et al. (2019) further contended that the term "sensory modulation" does not itself refer to an intervention and recommended that "sensory modulation intervention" should be used when referring to interventions. In this article the term sensory modulation intervention (SM intervention) is therefore used to refer to such interventions.

SM interventions are used to increase or decrease arousal depending on the individual's level of sensitivity and alertness (Champagne \& Stromberg, 2004). It involves the deliberate use of activities, behavioural strategies, specific equipment, and modification 
of the physical and social environment to assist the regulation of an individual's sensory experience (Lloyd, King \& Machingura, 2014; Sutton \& Nicholson, 2011). SM interventions are designed to give specific types and amounts of sensation, at specific times, for therapeutic purposes (Champagne et al., 2010). SM interventions involve empowering clients to selfmanage, and as such are thought to be congruent with recovery-oriented practice (Brown, 2002; Champagne \& Stromberg, 2004). It provides an alternative to coercive behavioural management methods such as seclusion and restraint (Chalmers, Harrison, Mollison, Molloy, \& Gray, 2012; Lloyd et al., 2014; Novak, Scanlan, Mccaul, Macdonald, \& Clarke, 2012; Yakov, Birur, Bearden, Aguilar, Ghelani, \& Fargason, 2018). Although there is growing literature that points to the efficacy of SM interventions, recent systematic reviews have concluded that generalisability of current findings is limited by the paucity of quality studies on this intervention generally (Scanlan and Novak, 2015) and in particular, with service users with schizophrenia (Machingura et al., 2018). A recent scoping review on SM interventions research revealed that most of the studies on efficacy were on service users using sensory rooms in psychiatric inpatient settings (Bailliard \& Whigham, 2017). They concluded that there is a need to 'expand' and 'extend' research on SM interventions in adults with mental illness (Bailliard \& Whigham, 2017).

\section{Studies examining service user and staff views}

Most of the available studies on SM interventions are quantitative studies and our study sought to qualitatively analyse the user's perspective. A New Zealand study on service user and staff experiences of using SM interventions in acute mental health units found that increasing service users' awareness was important (Sutton \& Nicholson, 2011). Champagne reported that service users should be empowered to be able to use the interventions appropriately and as needed, "to change the way they feel, change sensory processing patterns, and to increase occupation performance skills" (Champagne, 2009, p. 68). 
Effective SM intervention practice requires staff to increase service users' awareness of their sensory preferences (Champagne, 2009; Sutton \& Nicholson, 2011). Björkdahl, Perseius, Samuelsson, and Lindberg (2016) emailed a questionnaire to staff in a cross-sectional study exploring staff views of using SM interventions in a sensory room. They then derived themes from answers to open ended questions which included hopes and concerns, service user's self-care, and experiencing the room as a sanctuary. This study was however limited in that there was no interaction with an interviewer who could have helped to understand the responses more fully by probes and further questioning.

\section{Efficacy of sensory modulation in people with schizophrenia}

Several studies have reported on the benefits of SM interventions to service users. Adams-Leask, Varona, Dua, Baldock, Gerace, and Muir-Cochrane (2018) explored the benefits of SM interventions within a mental health emergency setting $(n=74)$ and found a statistically significant reduction in self-reported distress post SM intervention use.

Consumers also reported that SM intervention use was helpful, distracting, calming, and assisted in managing negative emotions and thoughts. Similar findings were reported by several other authors with similar service user groups in inpatient settings (Chalmers et al., 2012; Lloyd et al., 2014; Novak et al., 2012 and Sutton \& Nicholson, 2011). Those findings included opportunities for de-escalation, skill development, and increasing self-awareness and reduction in distress for consumers using SM interventions.

Although there is growing evidence to support the utility of implementing SM interventions, some factors can either facilitate or act as barriers for implementation. Training of staff in SM has been found to increase their knowledge, skills, and confidence in providing these interventions (Blackburn, Mckenna, Jackson, ... \& \& Furness, 2016; Meredith et al., 2018). Barriers identified in the literature include workplace culture and lack of accessibility and effective training (Meredith et al., 2018). The literature also points to the need to translate 
the knowledge into clinical practice using staff education and training on collaboration, leadership, supportive cultures, policy imperatives, and change management as well as SM intervention practice and resource development (Blackburn et al., 2016; Lee, Cox, Whitecross, Williams, \& Hollander, 2010).

Despite increased interest and use of SM interventions with adults with mental illness, studies on the efficacy to date, have mostly been from the staff's perspectives. To the authors' knowledge, this study is the first to investigate staff and service users with schizophrenia's views on SM interventions concurrently. The aim of this study was to examine efficacy of SM interventions from the lived experience of the users using an in-depth structured interview approach.

\section{Methods}

\section{Design}

This research project is a component of a larger mixed-methods research project investigating the efficacy of SM interventions for people with schizophrenia. The study commenced after receiving ethical clearance from Gold Coast University Hospital Human Ethics Review Committee (HREC/17/QGC/151) and Griffith University Human Research Ethics Committee (GU: 2019/079). A qualitative design was used as it is regarded as the preferred method to explore complex phenomena encountered by clinicians, providers, policy makers and consumers (Tong, Sainsbury \& Craig, 2007). We used qualitative content analysis to analyse the data with the main goal being to understand staff and service users' experiences of using SM interventions in a systematic and structured format (Graneheim, \& Lundman, 2004; Hsieh, \& Shannon, 2005, Tong et al., 2007). 


\section{Procedures}

Setting: The study was conducted in two large hospital and health services in Australia. Site 1 was a large hospital and health service with participants being recruited from 3 Psychiatric Acute Units and an Extended Treatment Psychiatric Unit. At Site 2, participants were recruited from a forensic hospital with a High Secure Unit, a Medium Secure Unit and an Extended Treatment Unit. All units had a bed capacity of 16 to 24 service users and care was delivered by a multidisciplinary team including occupational therapists, psychologists, social workers, nurses, and doctors.

Participants: This study involved service user participants who were adults with a diagnosis of schizophrenia using SM interventions $(n=13)$ and staff participants $(n=11)$ who were occupational therapists using SM with patients with schizophrenia. Some service users $(n=3)$ consented to participate but dropped out as they were transferred to another hospital and health service which was not involved in the study.

Participants were recruited from the two sites described above, following hospital and university ethical approval. Recruitment of service user participants was conducted using purposive sampling methods by occupational therapists who had been identified and trained as research collaborators and were employed at the two sites. Service user participants who met the selection criteria, had participated in our earlier quantitative study and used SM, and were well enough to engage in semi structured interviews, selected to provide rich, relevant, and diverse data pertinent to the study as recommended in the COREQ guidelines (Tong et al., 2007). Similarly, recruitment of staff participants was conducted using purposive sampling methods as suggested by COREQ guidelines (Tong et al., 2007). Staff who were using SM with patients with schizophrenia were invited to participate in the study. All participants provided individual written information and consent forms which they had to sign prior to involvement in the study. 
Data collection: Data were collected between November 2019 and August 2020. Data collection was impacted by COVID-19 restrictions. The interviews were audio recorded to allow transcription of interviews for data analysis. Transcriptions were done by a professional transcription service. Field notes of any contextual material were also written for use in the data analysis. These field notes included participants' reactions, and any non-verbal communications that were not captured on recordings. Prompts or probe questions were used to elicit more information where necessary during the interviews. No repeat interviews were conducted in this study.

We utilised semi-structured interviews to explore the experiences of participants and the meanings they attributed to those experiences. Reporting and implementation of this study followed the Consolidated Criteria for Reporting Qualitative Research (COREQ) guidelines (Tong et al., 2007).

For staff participants, prior to March 2020, face to face semi-structured interviews and a focus group discussion were conducted by the first author as detailed in Table 1. Semistructured interviews took about 45 minutes and the focus group discussion was over 60 minutes. From March 2020, data collection was conducted by the first author using Microsoft Teams, due to the COVID-19 restrictions in the country.

For service user participants, semi-structured interviews were conducted over a 45minute period per participant. Prior to March 2020, face to face semi-structured interviews were conducted by the first author and by 2 occupational therapists identified and trained by the first author to conduct the interviews. Each of the occupational therapists conducted two interviews and the rest were conducted by the first author. From March 2020, data collection was conducted by the first author over the telephone, due to the COVID-19 restrictions in the country. Due to health service requirements for data collection using remote technologies, an 
occupational therapist working with the client would sit in the room with the service user

during the telephone interview with the researcher.

Table 1: Interview questions

\begin{tabular}{|c|c|c|}
\hline \multicolumn{2}{|c|}{ Patients ( $n=13$ ) } & Staff (n-11) \\
\hline & $\begin{array}{l}\text { Can you tell me about your experience of using sensory } \\
\text { tools? } \\
\text { Prompt 1: What, when, where, how, and why do you use } \\
\text { sensory interventions? }\end{array}$ & $\begin{array}{l}\text { 1. Can you tell me about your experience of using sensory } \\
\text { modulation with patients with schizophrenia? } \\
\text { Prompt 1: What, when, where, how, and why do you use } \\
\text { sensory modulation? } \\
\text { Prompt 2: I want you to think back to a time when you did } \\
\text { not have this knowledge around using these different } \\
\text { sensory techniques. }\end{array}$ \\
\hline & $\begin{array}{l}\text { Can you tell me about how well or not well you think these } \\
\text { tools and techniques work for you? It will be great if you } \\
\text { have some examples. } \\
\text { Prompt 1: How do you choose whether to use sensory } \\
\text { modulation or not to? } \\
\text { Prompt 2: What is your experience of using sensory } \\
\text { modulation to calm or alert yourself? } \\
\text { Prompt 3: Which tools or techniques were helpful and } \\
\text { which ones did not help? Is there one technique or tool or a } \\
\text { group of tools that you find the most useful? } \\
\text { Prompt } 4 \text { (if needed): I want you to think back to a time } \\
\text { when you used sensory modulation. Describe how you were } \\
\text { before, during and after using the Sensory modulation. Is } \\
\text { there anything that stood out in your mind about the } \\
\text { experience? }\end{array}$ & $\begin{array}{l}\text { 2. Can you tell me about how well or not well you think these } \\
\text { tools and techniques work for your patients with } \\
\text { schizophrenia? It will be great if you have some examples. } \\
\text { Prompt 1: How do you choose whether to offer sensory } \\
\text { modulation to a specific consumer or not to? } \\
\text { Prompt 2: What is your experience of using sensory } \\
\text { modulation to calm patients or alert patients? } \\
\text { Prompt 3: Which tools or techniques were helpful and } \\
\text { which ones did not help? Is there one technique or tool or a } \\
\text { group of tools that you find the most useful? } \\
\text { Prompt } 4 \text { (if needed): I want you to think back to a time } \\
\text { when you used sensory modulation. Describe how the } \\
\text { patient was before, during and after using the Sensory } \\
\text { modulation. Is there anything that stood out in your mind } \\
\text { about the experience? }\end{array}$ \\
\hline & $\begin{array}{l}\text { Can you tell me how you were introduced to using these } \\
\text { sensory tools and techniques? } \\
\text { Prompt 1: How did you learn to use these tools to help } \\
\text { yourself? } \\
\text { Prompt 2: If they attended a sensory course: Can you tell } \\
\text { me a little bit about the course and what you learnt? }\end{array}$ & $\begin{array}{l}\text { 3. Can you tell me how you were introduced to using these } \\
\text { sensory tools and techniques? } \\
\text { Prompt 1: How did you learn to use these tools to help your } \\
\text { patients? } \\
\text { Prompt 2: If they attended a sensory course: Can you tell } \\
\text { me a little bit about the course and what you learnt? }\end{array}$ \\
\hline & $\begin{array}{l}\text { Do you see yourself continuing to use sensory modulation } \\
\text { into the future? If so why and if not, why not? } \\
\text { Prompt 1: What are some of the barriers and facilitators } \\
\text { you have experienced in using sensory modulation? } \\
\text { Prompt 2: Can you tell me about things you would change } \\
\text { about your experience that would make you want to use } \\
\text { the sensory tools and techniques more or less into the } \\
\text { future? }\end{array}$ & $\begin{array}{l}\text { 4. Do you see yourself continuing to use sensory modulation } \\
\text { into the future? If so why and for whom; and if not, why } \\
\text { not? } \\
\text { Prompt 1: What are some of the barriers and facilitators } \\
\text { you have experienced in using sensory modulation with } \\
\text { patients with schizophrenia? } \\
\text { Prompt 2: Can you tell me about things you would change } \\
\text { about your experience that would make you want to use } \\
\text { the sensory tools and techniques more or less with patients } \\
\text { into the future? }\end{array}$ \\
\hline
\end{tabular}

The interview schedule, detailed in Table 1 and used by all interviewers, was developed using the literature and refined by the research team, including input from occupational therapists working at the two research sites. Audio recordings of the interviews were manually transcribed verbatim by a professional transcription service and checked by 
the research team. Audio recordings and transcripts served both as data and as checks that interview processes were consistent.

\section{Data analysis}

Data were analysed using qualitative content analysis (Hsieh \& Shannon, 2005). We used a data driven inductive method to generate themes from the data. The initial coding was done by the first author T.M and a sample of 6 transcripts was independently coded by S.G, a graduate entry masters student. Categories were derived from the data after reading all the transcribed data. Following this a codebook was developed to use as a coding instrument. Two independent reviewers were then asked to review the coding. The researchers had $>85 \%$ level of agreement across judgements in coding which is within the acceptable margin for reliability (Miles \& Huberman, 1994). Miles and Huberman (1994) suggest that an inter rate reliability of $80 \%$ agreement between coders on $95 \%$ of the codes is sufficient agreement. The views of both staff and service users were described in terms of identified codes and categories and organised into themes. This approach allowed the researchers to gain information from the study participants without imposing preconceived categories. The themes were then discussed with participants who confirmed them as reflective of their views in a later session. Discussion of themes with staff participants occurred via videoconferences. Service user participants reviewed themes during meetings with their clinicians who were occupational therapists trained by the first author.

\section{Results}

\section{Participant characteristics}

This study had 11 staff participants and 13 service users with schizophrenia. Three of the staff participants had less than 5 years of experience, three had between 5 and 10 years 
and 5 had more than 10 years of experience as a registered occupational therapist as detailed in Table 2. Service users involved in the study had a mean age of 36.5 years $(S D=5.62)$ and a diagnosis of schizophrenia as diagnosed by the treating psychiatrist. Most of the service users were Caucasian females $(n=11)$ and two were male Caucasians. Service user participant characteristics are not detailed due to the small sample and the possibility that they could be identified from those details.

Table 2: Staff participants demographic details

\begin{tabular}{|l|l|l|l|}
\hline Variable & Description & Count $(n=11)$ & $\%$ \\
\hline Age in years & $20-30$ & 2 & $18 \%$ \\
& $31-40$ & 5 & $46 \%$ \\
& $41-50$ & 3 & $27 \%$ \\
& $>50$ & 1 & $9 \%$ \\
\hline Ethnicity & Caucasian & 7 & $64 \%$ \\
& Aboriginal & 1 & $9 \%$ \\
& Asian & 3 & $27 \%$ \\
\hline Gender & Male & 1 & $10 \%$ \\
& Female & 10 & $90 \%$ \\
\hline Years post & $0-5$ & 3 & $27 \%$ \\
Qualification as an & $6-10$ & 1 & $9 \%$ \\
OT & $11-15$ & 3 & $27 \%$ \\
& $>15$ & 4 & $36 \%$ \\
\hline Training in sensory & Informal & 9 & $82 \%$ \\
modulation received & Formal $<1$ week & 2 & $18 \%$ \\
& Formal $>1$ week & 0 & $0 \%$ \\
\hline
\end{tabular}

\section{Themes}

The five themes that emerged from this study were (1) Service user education on the sensory approach is key, (2) A variety of tools should be tried, (3) Sensory modulation provides a valued treatment option, (4) There are challenges of managing perceived risk at an organisational level and (5) There is a shortage of accessible and effective training. There were however some differences in the perceptions of service users $(\mathrm{P})$ as compared to those of staff (S). The themes from both service users (U) and staff participants (S) are detailed in Table 3. 
Table 3: Themes from staff and service user views

\begin{tabular}{|c|c|c|c|}
\hline $\begin{array}{l}\text { Broad } \\
\text { Category/ } \\
\text { Question }\end{array}$ & $\begin{array}{l}\text { STAFF VIEWS - } \\
\text { Coded themes (S) }\end{array}$ & $\begin{array}{l}\text { PATIENT VIEWS- } \\
\text { Coded themes }(\mathrm{U})\end{array}$ & MAJOR THEMES \\
\hline $\begin{array}{l}\text { What is } \\
\text { effective when } \\
\text { using sensory } \\
\text { modulation } \\
\text { interventions? }\end{array}$ & - Variety of tools & $\begin{array}{l}\text { - } \begin{array}{l}\text { Variety of } \\
\text { tools }\end{array} \\
\text { tol }\end{array}$ & $\begin{array}{l}\text { - } \begin{array}{l}\text { Variety of } \\
\text { tools }\end{array} \\
\text { t }\end{array}$ \\
\hline $\begin{array}{l}\text { How are } \\
\text { sensory } \\
\text { interventions } \\
\text { implemented to } \\
\text { be effective? }\end{array}$ & $\begin{array}{ll}\text { - } & \text { Variety of tools } \\
\text { - } & \text { Service user } \\
\text { education }\end{array}$ & $\begin{array}{ll}\text { - } & \text { Variety of } \\
\text { tools } \\
\text { - } & \text { Service user } \\
\text { education }\end{array}$ & $\begin{array}{ll}\text { - } & \text { Variety of } \\
\text { tools } \\
\text { - } & \text { Service user } \\
\text { education }\end{array}$ \\
\hline $\begin{array}{l}\text { What are the } \\
\text { facilitators? }\end{array}$ & $\begin{array}{ll}\text { - } & \text { Accessible } \\
\text { training } \\
\text { - Service user } \\
\text { education } \\
\text { - Valued } \\
\text { treatment } \\
\text { option } \\
\end{array}$ & $\begin{array}{ll}\text { - Accessible } \\
\text { education } \\
\text { - Service user } \\
\text { education } \\
\text { - Valued } \\
\text { treatment } \\
\text { option } \\
\end{array}$ & $\begin{array}{ll}\text { - Accessible } \\
\text { training } \\
\text { - Service user } \\
\text { education } \\
\text { - Valued } \\
\text { treatment } \\
\text { option } \\
\end{array}$ \\
\hline $\begin{array}{l}\text { What are the } \\
\text { barriers to } \\
\text { using SM? }\end{array}$ & $\begin{array}{l}\text { Lack of training } \\
\text { opportunities. } \\
\text { - } \quad \text { Lack of } \\
\text { organisational } \\
\text { support due to } \\
\text { perceived risk } \\
\text { of using } \\
\text { sensory tools } \\
\text { - Service user } \\
\text { level of } \\
\text { wellness/ } \\
\text { insight }\end{array}$ & 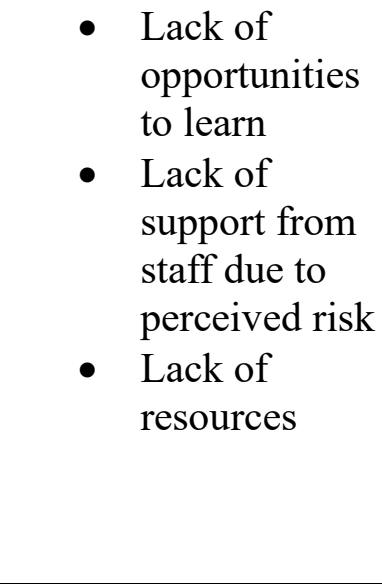 & $\begin{array}{l}\text { - Challenges of } \\
\text { managing } \\
\text { perceived risk } \\
\text { at an } \\
\text { organisational } \\
\text { level } \\
\text { - Shortage of } \\
\text { accessible and } \\
\text { effective } \\
\text { training. }\end{array}$ \\
\hline
\end{tabular}

Theme one: Service user education on the sensory approach is key

Staff stated that a key factor in using sensory modulation is ensuring that service users and/or their carers' are aware of their sensory preferences. They also added that service users should be educated about the intervention, what it is, when and how to use it so they can selfmanage.

"I think, in the other areas, giving people the education around sensory approaches, and going on that polyvagal theory, and actually educating around that - that actually helps 
give people a lot more insight around it, and they'll all of a sudden become more aware of their environment, aware of their activities, and commence to make that mindful approach to how they are being stimulated, and how they can regulate themselves better". (S 7)

Sensory awareness was reported by staff to be able to be developed by service users with the capacity to do so. One staff member pointed out the need to target the right people likely to benefit from the intervention by stating:

"So, if the person has the capacity to implement their own strategies - they need to get why they're doing it and they need to go, yep, sweet, I get it, that's why I'm doing it". (S 3)

This was further supported by another staff member who stressed the need to understand the concepts by stating:

"I always find there's good mileage when you start going through the neuroscience of it and you're actually helping them to get an understanding themselves and how they've been wired, should we say, how what they're experiencing is impacting that". (S 4)

This was summed up as important for a user to be able to self-manage:

"I suppose then it's about planning how to use that information to better support themselves and to learn and understand themselves". (S 1)

Several staff reported that it was important for service users to have a certain level of wellness so that they can benefit from sensory modulation:

"I think so long as the person is able to take in some things and not acutely psychotic or acutely suicidally depressed, there's always some possibility of interventions at any stage".

Service users were however not as convinced in the importance of having wellness but agreed that they needed to understand the intervention so they can own it. Some service users articulated a sense of control they had by stating, 
"I answered the questionnaires on different types of smells, textures ... to see what I thought would work. We went through quite a bit of that. They brought in different options for me, and it was up to me whether I wanted them in the sensory box or not". (U 3)

\section{Theme two: A variety of tools should be tried}

A key and frequent view from both staff and service users was that a variety of tools needed to be trialled to find one that works for the user.

"The issue is trying to find the tool, or tools, or strategies that work best for that person and there's no prescription for that. It's pretty much around trial and error. We can use our assessments to guide that, but it really is around trial and error. So, I think the key is finding the right tool and then it can be extremely powerful". (S 1)

Several service users stated that they also find using a variety of tools at the same time very beneficial.

"I've got a chest full of different sensory things. So, it's not the same thing I have to use all the time. I've got a variety of stuff so it's refreshing”. (U 4)

"Well, I can use several different ones at the same time. Yeah, so it doesn't just have to be one thing. I have a line of things and just go through them until I can go through all of them until I feel better. Sometimes I just need to use one or two but sometimes I need to use more. I think you should persist”. (U 5)

Service users and staff were unanimous in their view that sensory items are neither alerting nor calming and that such effects were dependent on the person using the items. They were of the view that there were no 'power tools' or items that could be prescribed to elicit a specified effect. They were of the view that one must try the tool and if it does not work then try another one. 
"I can access my sensory box when I need to. At the time I feel really, what's the word, unsettled, agitated, and my mind, my thoughts racing. So, I try and - each time it's something different”. (U 3)

The staff were of the view that the effects of the tools used would depend on the user's preferences. They were of the view that they are less dependent on the tool's characteristics but more on the user's sensory preferences.

"I feel like, regardless of what the person's diagnosis is, sour lollies tend to work and they either work for grounding or for that more alerting when someone's hypo-aroused. So, they can work both ways". (S 2)

\section{Theme three: An alternative treatment option}

There was agreement between staff and service users that sensory modulation adds to the milieu of treatment options available to service users with schizophrenia. There was consensus on the view that current treatment options are not enough.

"I don't know, another set of interventions that I can use to actually get somebody in the space to be able to engage in their meaningful occupations. So, I just feel like it's added so beautifully to the work that we do". (S 2)

"But having sensory modulation has just been a whole, other set of interventions that I can use to actually get somebody in the space to be able to engage in their meaningful occupations....something that really makes them feel good, helps them get focused, helps them to become engaged and it also gives them another lens with which to look through things. I mean, particularly with consumers who are psychotic or who have schizophrenia". 
All service users who participated in the study agreed that SM interventions added something different or new for them and they reported that sensory modulation works for them. Several service users regarded SM as an alternative to medications.

"I think it works better without the medication". (U 3)

"I need extra things to do because I've got a heart condition so they can't give me a lot of medication. Yeah, so, I think it will be something that I use for the rest of my life". (U 4)

Both staff and service users who participated in the study were therefore of the view that this was a much-needed additional tool for them to use with their service users or on themselves respectively. This view appears to stem from all staff and service users' experiences on how SM helps manage symptoms of schizophrenia. The effects were reported on both positive and negative symptoms of schizophrenia. Reported effects on positive symptoms were that it helps with managing voices, helps with settling unwanted thoughts including suicidality and had a desired effect on delusions and general emotional regulation. "I found it hard to concentrate because when I hear the voices, I tend to get a bit weird or crazy. With the sensory items, if I ever hear voices and use them it calms me down and it's easy to relax more”. (U 1)

"If the voices get loud, I put the music on to take their sound away". (U 3)

Reported effects on negative symptoms were that SM helps with arousal, helps with sleep, improves mood, improves energy levels, improves concentration and reduces stress and anxiety.

"It actually helps you be more mindful. You won't be worrying about something in the past or you won't be worrying about something that you're afraid might happen". (U 1) 
"But if I'm upset, I've got this putty stuff that you put your fingers in and it makes funny noises. When I'm feeling down and depressed, I use that and it makes me laugh”. (U 3)

When service users were asked about their experiences of using SM (see questions in Table 1), the most frequently reported effects of SM were enjoyment $(n=11)$, distraction from negative thoughts $(n=8)$, calming $(n=7)$, and assistance to sleep $(n=6)$. This was in response to a question we asked on their experiences of using SM which is detailed in Table 1. They also reported positive effects on preparation for participation in occupations.

"To make me feel more energized I would drink something that wakes me up like lemonade. I also put hand lotion on or use stress oil”. (U 11)

\section{Theme four: Challenges of managing perceived risk at an organisational level}

Even though other barriers were mentioned by both staff and service users, a key barrier that both alluded to was institutional concerns about risk management which hindered the use of the intervention.

"I think a big factor we need to consider from a service perspective as well, is the environment, and I'm aware in some of the high acuity areas, you can't have this, you can't have that, they can't do this, and I mean including not even being able allowed to have a piece of paper”. (S 2)

Staff reported that it was challenging to put the knowledge into practice due to an organisational focus on perceived risk. One participant stated,

"I think there's a component, particularly in this field, where it's not just simply learning how to do the practice, but also how to implement the practice, within an environment, within the policies, ...".

Another participant pointed out frustrations with the implementation difficulties and suggested a cultural change was needed. 
"So that can be quite frustrating because the amount of effort I put in and what I get back is not matching up at the moment... That's the nursing staff and that's cultural change and that you've just got to chip away at that. That's not something that's going to happen quickly”. (S 4)

This cultural change was seen as the best way forward with some staff referring to it as a "war" that needed to be won.

"So, as a facilitator, if you can get staff on board, if people value the work you do and can see that it works, can see that it's effective, then the war's won". S 1)

Service users however were more concerned about what resources they had access to which was also constrained by risk management practices. They reported experiences of not having access to the tools and environments they need, when they needed them. One service user related his experience of being locked up for months.

“Geez, I wake up in the morning, I put my headphones on, have breakfast and I'm locked up until - I've been locked up for about a month and a half here, like can't even go outside to have a smoke”. (U 7)

\section{Theme five: Shortage of accessible and effective training}

Most staff using the intervention with service users were never formally trained and learnt by trial and error.

"I find that the university training hugely varies between the different institutions. I think for myself personally, a lot of the training is actually after you get into the workplace”. (S 1)

"Yeah, my experiences of sensory modulation and therapy on that is very, very limited, it's based on what I've experienced on placements only”. (S 7) 
Most service users lamented the need for information and education. One service user lamented the lack of time devoted to the intervention.

"I would have liked more time to test out different items in the group. Having more one on one time with you would have been more helpful." (U 8)

Staff pointed to the lack of research evidence to guide practice as a barrier to the availability of training. Staff who wanted to train pointed out that there are no training opportunities available.

"Because I basically just had to research it myself to learn how to interpret the scores and to write a report. Even still, I still sort of second guess myself and confuse myself because of the language of the screening tool”. (S 3)

Paucity of research evidence to guide practice was also mentioned as a barrier.

"Then like okay it's working but we don't have the proper research so it's difficult to say how much it's effective is an evidence-based point of view”. (S 2)

Some staff also added that this lack of evidence was further compounded by the fact that the intervention lacks face validity.

"So, if people see, for instance, a stress ball, and they think, oh cute, that's going to solve all their problems, isn't it? So, we've really got to consider the face validity of what we're doing as well along the way'. (S 2)

Professional development is rare and offered mostly by occupational therapists who have been self-taught or learnt from an expert/ academic/ researcher in this area of practice. There are no formal courses available for people to be certified/ trained in the use of this intervention. Staff stated that they are expected and encouraged to just do it. 
"I would say that I've always been encouraged to use it because the workplace that I was in previously was very enthusiastic about using sensory interventions and even when I was still trying to learn about it”. (S 3)

Most staff are self-taught using a variety of methods including trial and error, observing others, research and reading about it. Most service users report having been introduced to the intervention by an occupational therapist. Some service users also report having been introduced to the intervention by other staff including psychologists $(n=2)$, nurses $(n=2)$ and doctors $(n=2)$. This was in response to a question on how participants were introduced to SM which is detailed in Table 1.

\section{Discussion}

The findings of this study suggest that both staff and service users had similar views on the themes of educating users, trying a variety of tools, SM interventions being a valued treatment option, and the challenges of managing risk. Service users, however, did not report on the shortage of accessible and effective training as a major issue for them whereas this was a theme raised by staff. The other differences between staff and service user views were on specific details within the themes as discussed below.

There was agreement between staff and service users on the first theme of the need to educate service users on the approach prior to them using sensory interventions. Staff were of the view that service users needed to have some level of insight to benefit from the education, however, service users thought they needed to be trained to be able to help themselves using SM interventions. Although there are different views on what is needed both groups agree that developing knowledge on SM interventions is critical. Educating the service user or their carer helps with gaining sensory awareness and knowing when to use the intervention. This is consistent with previous studies which highlighted the importance of self-awareness and the 
need to use SM interventions to self-manage (Champagne 2004; Champagne, 2009; Sutton \& Nicholson, 2011). Barbic et al. (2019) also reported that a theme from participants in their study was there is a need for educating participants on the intervention. This previous study was however conducted with participants of mixed diagnosis and in a sensory room environment. Our study sought the views specifically from those participants with schizophrenia rather than those of a mixed population of mental health service users.

The theme on use of a variety of tools has not been explicitly reported in previous studies. It is, however, a logical theme given the developing and accepted theory on sensory preferences (Brown, Karim, \& Steuter, 2020). All participants were of the view that what works for one person may not work for another person and that one item can be calming to one person and alerting to another. This idea has been previously posited by Champagne $(2009 ; 2011)$ and is consistent with Dunn's (1997) theory that people have different sensory processing patterns which result from the interaction of their neurological threshold with their behavioural self-regulation strategy.

Findings from this study also suggest that sensory modulation provides a valued treatment option. The participants of this study reported positive effects on both positive and negative symptoms of schizophrenia. Previous research has described benefits on emotional regulation and distress (Adams-Leak et al., 2018; Champagne \& Sayer, 2008; Chalmers et al., 2012; Lloyd et al., 2014; Novak et al., 2012; Sutton \& Nicholson, 2011 and Yakov et al., 2018). This direct link to specific symptoms of schizophrenia such as a reduction in voices, reduction in suicidal and self-harming thoughts, increase in energy levels and increase in motivation is, however, a new finding. Similarly, a recent study on health provider and service user experiences of using a sensory room reported that a theme that sensory modulation was an alternative to current practice (Barbic et al., 2019). 
The fourth, and fifth themes that emerged from this study appear to be the most consistently reported on barriers to the use and implementation of SM interventions (Blackburn et al., 2016; Lee et al, 2010; Meredith et al., 2018). The fact that there are challenges of managing perceived risk at an organisational level and a shortage of accessible and effective training opportunities exists in organisations is not new (Blackburn et al., 2016; Meredith et al., 2018). The risk averse approach seen in organisations is noted in the literature as being caused by a lack of guidance at a policy and practice level (Holley, Chambers, \& Gillard, 2016). Despite this being known, there appears to have been limited change in organisations over the years. The fact that we also found that participants are of the view that there is a lack of knowledge translation skills might also be a perpetuating factor. These skills are crucial to implementation and changing organisational culture. The translation of learning into practice requires knowledge acquisition and reflection (Blackburn et al., 2016). Our participants however clearly lacked access to effective training opportunities.

\section{Suggestions for teaching, practice and future research}

Firstly, service users see sensory modulation interventions as a much-needed addition to the treatment milieu available to service users with schizophrenia. We suggest to service providers that SM interventions be considered for being made available to service users who may choose, want, or need to access them.

Secondly, where a service provider has chosen to implement SM interventions then we suggest a considered approach of implementation that balances both risks and benefits of implementation within the specific therapeutic context. 
Thirdly, where staff are charged with leading the implementation of SM interventions, we suggest that they should also upskill in their knowledge translation skills including change management skills in addition to their skills in SM interventions.

Fourthly, we suggest that service users with schizophrenia should be given opportunities to learn about the intervention, try a variety of tools and build their sensory selfawareness as part of the sensory assessment process.

Finally, we suggest there is a need for more research to better understand the efficacy of the intervention and the conditions which facilitate or act as barriers. Using quantitative methodologies would be helpful in further testing the themes found in this study.

\section{Limitations}

Data were collected during the COVID-19 pandemic period which reduced our access to participants. This had reduced the number of participants that could undertake the study. The study design, however, was qualitative, so the impact of recruiting many participants was minimised by doing in depth interviews. The method of data collection had also to be changed from face to face to telephone interviews which reduced the number of service users wanting to participate. This affected the study in that some of the meanings which could be derived from direct observations were not possible to achieve. Using an experienced occupational therapist who would sit in the same room with the client during telephone interviews was done to mitigate this limitation.

The first author and some of the researchers who conducted interviews were occupational therapists who use SM interventions and may have been biased towards a positive view of the intervention. Generalisability of conclusions is limited by the small sample size consisting of a homogenous group of service users who were all white Caucasians. Generalisability is also limited by the validity and reliability of qualitative 
content analysis used in this research. We, nevertheless, used multiple classifiers to arrive at an agreed category definition. Coding errors were minimised by having 2 reviewers and a third reviewer for resolving disagreements. We had $>85 \%$ level of agreement across judgements in coding which is within the acceptable margin for reliability.

\section{Conclusion}

The findings of this study suggest that both service users and staff experienced SM interventions as effective for those with schizophrenia and they viewed this intervention as an alternative and needed addition to available treatment options. Unfortunately, the key barrier to using this intervention articulated by both staff and service users was the challenge of managing perceived risk at an organisational level against the potential benefits.

Organisations need to focus on cultural change if they wish to be client-centred and achieve desired outcomes for their service users. More research is needed to further explore the reported benefits of this intervention using quantitative methods. 


\section{References}

Adams-Leask, K., Varona, L., Dua, C., Baldock, M., Gerace, A., \& Muir-Cochrane, E. (2018). The benefits of sensory modulation on levels of distress for consumers in a mental health emergency setting. Australasian Psychiatry: Bulletin of the Royal Australian and New Zealand College of Psychiatrists, 26(5), 514-519. https://doi.org/10.1177/1039856217751988

Bailliard, A., \& Whigham, S. (2017). Linking Neuroscience, Function, and Intervention: A Scoping Review of Sensory Processing and Mental Illness. The American Journal of Occupational Therapy: Official Publication of the American Occupational Therapy Association., 71(5). https://doi.org/10.5014/ajot.2017.024497

Barbic, S., Chan, N., Rangi, A., Bradley, J., Pattison, R., Brockmeyer, K., Leznoff, S., Smolski, Y., Toor, G., Bray, B., Leon, A., Jenkins, M., Mathias, S., \& Shiu, C. (2019). Health provider and service-user experiences of sensory modulation rooms in an acute inpatient psychiatry setting. PLoS ONE, 14(11), e0225238. https://doi.org/10.1371/journal.pone.0225238

Bar-Shalita, T., Deutsch, L., Honigman, L., \& Weissman-Fogel I. (2015). Ecological aspects of pain in sensory modulation disorder. Research in Developmental Disability, 45(46), $157-167$.

Blackburn, J., Mckenna, B., Jackson, B., Hitch, D., Benitez, J., Mclennan, C., \& Furness, T. (2016). Educating Mental Health Clinicians About Sensory Modulation to Enhance Clinical Practice in a Youth Acute Inpatient Mental Health Unit: A Feasibility Study. Issues in Mental Health Nursing: On Aggression and Violence, 37(7), 517525.https://doi.org/10.1080/01612840.2016.1184361

Björkdahl, A., Perseius, K., Samuelsson, M., \& Lindberg, M. (2016). Sensory rooms in psychiatric inpatient care: Staff experiences. International Journal of Mental Health Nursing, 25(5), 472-479. https://doi.org/10.1111/inm.12205

Brown, C., Cromwell, R., Filion, D., Dunn, W., \& Tollefson, N. (2002). Sensory processing in schizophrenia: missing and avoiding information. Schizophrenia Research, 55(1-2), 187-195. https://doi.org/10.1016/S0920-9964(01)00255-9

Brown, C., Karim, R., \& Steuter, M. (2020). Retrospective Analysis of Studies Examining Sensory Processing Preferences in People With a Psychiatric Condition. The American Journal of Occupational Therapy: Official Publication of the American Occupational Therapy Association., 74(4). https://doi.org/10.5014/ajot.2020.038463

Brown, A., Tse, T., \& Fortune, T. (2019). Defining sensory modulation: A review of the concept and a contemporary definition for application by occupational therapists. Scandinavian Journal of Occupational Therapy, 26(7), 515-523. https://doi.org/10.1080/11038128.2018.1509370

Chalmers, A., Harrison, S., Mollison, K., Molloy, N., \& Gray, K. (2012). Establishing sensory-based approaches in mental health inpatient care: a multidisciplinary approach. Australasian Psychiatry, 20(1), 35-39. https://doi.org/10.1177/1039856211430146 
Champagne, T. (2009). New powers for naturopaths. CMAJ, 180(13), 1331. doi: 10.1503/cmaj.1090037

Champagne, T. (2011). Sensory modulation and environment: Essential elements of occupation. (3rd ed.). Southampton, MA: Champagne Conferences.

Champagne, T., \& Sayer, E. (2008). The effects of the use of the sensory room in psychiatry. In T. Champagne (Ed.), Sensory modulation and environment: Essential elements of occupation. (3rd ed.). Southampton, MA: Champagne Conferences.

Champagne, T., \& Stromberg, N. (2004). Sensory approaches in inpatient psychiatric settings: innovative alternatives to seclusion \& restraint. Journal of Psychosocial Nursing and Mental Health Services, 42(9), 34-44. https://doi.org/10.3928/02793695$\underline{20040301-01}$

Champagne, T., Koomar, J, \& Olson, L. (2010). Sensory processing evaluation and intervention in mental health. OT Practice, 15(5), CE1-CE8. Retrieved from https://search-proquestcom.ezproxy.bond.edu.au/docview/232421976?accountid=26503

Dunn, W. (1997). The impact of sensory processing abilities on the daily lives of young children and their families: A conceptual model. Infants and Young Children, 9 (4), 23 35 .

Graneheim, U., \& Lundman, B. (2004). Qualitative content analysis in nursing research: concepts, procedures and measures to achieve trustworthiness. Nurse Education Today, 24(2), 105-112. https://doi.org/10.1016/j.nedt.2003.10.001

Holley, J., Chambers, M., \& Gillard, S. (2016). The impact of risk management practice upon the implementation of recovery-oriented care in community mental health services: a qualitative investigation. Journal of Mental Health, 25(4), 315-322. https://doi.org/10.3109/09638237.2015.1124402

Hsieh, H., \& Shannon, S. (2005). Three Approaches to Qualitative Content Analysis. Qualitative Health Research, 15(9), 1277-1288. https://doi.org/10.1177/1049732305276687

Lee, S., Cox, A., Whitecross, F., Williams, P., \& Hollander, Y. (2010). Sensory assessment and therapy to help reduce seclusion use with service users needing psychiatric intensive care. Journal of Psychiatric Intensive Care, 6(2), 83-90. https://doi.org/10.1017/S1742646410000014

Lipskaya-Velikovsky, L., Bar-Shalita, T., \& Bart, O. (2015). Sensory modulation and dailylife participation in people with schizophrenia. Comprehensive Psychiatry, 58, 130137. https://doi.org/10.1016/j.comppsych.2014.12.009

Lloyd, C., King, R., \& Machingura, T. (2014). An investigation into the effectiveness of sensory modulation in reducing seclusion within an acute mental health unit. Advances in Mental Health, 12(2), 93-100. https://doi.org/10.1080/18374905.2014.11081887

Machingura, T., Shum, D., Molineux, M., \& Lloyd, C. (2018). Effectiveness of Sensory Modulation in Treating Sensory Modulation Disorders in Adults with Schizophrenia: a 
Systematic Literature Review. International Journal of Mental Health and Addiction, 16(3), 764-780. https://doi.org/10.1007/s11469-017-9807-2

Meredith, P., Yeates, H., Greaves, A., Taylor, M., Slattery, M., Charters, M., \& Hill, M. (2018). Preparing mental health professionals for new directions in mental health practice: Evaluating the sensory approaches e-learning training package. International Journal of Mental Health Nursing, 27(1), 106-115. https://doi.org/10.1111/inm.12299

Miles, M. B., \& Huberman, A. M. (1994). Qualitative data analysis: An expanded sourcebook (Second Edi). Sage Publications.

Novak, T., Scanlan, J., Mccaul, D., Macdonald, N., \& Clarke, T. (2012). Pilot study of a sensory room in an acute inpatient psychiatric unit. Australasian Psychiatry, 20(5), 401-406. https://doi.org/10.1177/1039856212459585

Owen, M., Sawa, A., \& Mortensen, P. (2016). Schizophrenia. Lancet (London, England), 388(10039), 86-97. https://doi.org/10.1016/S0140-6736(15)01121-6

Postmes, L., Sno, H. N., Goedhart, S., van der Stel, J., Heering, H. D., \& de Haan, L. (2014). Schizophrenia as a self-disorder due to perceptual incoherence. Schizophrenia Research, 152(1), 41-50. doi: http://dx.doi.org/10.1016/j.schres.2013.07.027

Scanlan, J., \& Novak, T. (2015). Sensory approaches in mental health: A scoping review [Review of Sensory approaches in mental health: A scoping review]. Australian Occupational Therapy Journal, 62(5), 277-285. https://doi.org/10.1111/1440$\underline{1630.12224}$

Sinclair, C., Meredith, P., Strong, J., \& Chalkiadis, G. A. (2019). Sensory Modulation. The Clinical Journal of Pain, 35(2), 121-132. DOI:10.1097/AJP.0000000000000663

Sutton, D., \& Nicholson, E. (2011). Sensory modulation in acute mental health wards: A qualitative study of staff and service user perspectives. Auckland, New Zealand: Te Pou o Te Whakaaro Nui. Retrieved from http://www.tepou.co.nz/uploads/files/resourceassets/sensory_modulation_in_acute_mental_health_wards.pdf

Tong A, Sainsbury P, Craig J. (2007). Consolidated criteria for reporting qualitative research (COREQ): a 32-item checklist for interviews and focus groups. Int J Qual Health Care, 19(6):349-357.

Vlcek, P., Bob, P., \& Raboch, J. (2014). Sensory disturbances, inhibitory deficits, and the P50 wave in schizophrenia. Neuropsychiatric Disease \& Treatment 10, 1309-1315.

Yakov, S., Birur, B., Bearden, M., Aguilar, B., Ghelani, K., \& Fargason, R. (2018). Sensory Reduction on the General Milieu of a High-Acuity Inpatient Psychiatric Unit to Prevent Use of Physical Restraints: A Successful Open Quality Improvement Trial. Journal of the American Psychiatric Nurses Association, 24(2), 133-144. https://doi.org/10.1177/1078390317736136 